\title{
TRANSPLANTE HEPÁTICO EM PACIENTE SOROPOSITIVO PARA O HIV
}

\author{
Liver transplantation in an HIV positive patient \\ Alexandre Coutinho Teixeira de FREITAS, Wagner SOBOTTKA, Mônica Beatriz PAROLIN, \\ Jorge Eduardo Fouto MATIAS, Júlio Cezar Uili COELHO
}

\section{INTRODUÇÃO}

Nos últimos anos os soropositivos para o HIV passaram a apresentar expectativa de vida prolongada devido ao uso da terapia antiretroviral altamente ativa. Isso causou incremento do número de pacientes portadores de infecções virais crônicas como a hepatite B e C. Na Espanha, aproximadamente $5 \%$ a $7 \%$ dos pacientes soropositivos para o HIV apresentam co-infecção pelo vírus da hepatite $\mathrm{B}$ e $45 \%$ a $50 \%$ pelo vírus da hepatite $\mathrm{C}^{1}$. Em alguns centros o transplante hepático foi realizado com sucesso nessa situação ${ }^{2,3}$.

O objetivo desse estudo é relatar um caso de transplante hepático devido à cirrose secundária à infecção pelo vírus da hepatite B em paciente soropositivo para o HIV.

\section{RELATO DO CASO}

Homem com 51 anos de idade, soropositivo para o HIV em terapia antiretroviral evoluiu com resistência à lamivudina que foi substituída por adefovir e posteriormente por tenofovir Nunca apresentou infecções oportunísticas relacionadas ao HIV. Evoluiu com cirrose hepática pelo vírus da hepatite $\mathrm{B}$ e carcinoma hepatocelular e foi submetido à transplante hepático cadavérico.

$\mathrm{Na}$ avaliação pré-operatória apresentou PCR quan-

Trabalho realizado no Serviço de Transplante Hepático do Hospital de Clínicas da Universidade Federal do Paraná, Curitiba, PR, Brasil

Endereço para correspondência: Alexandre Coutinho

Teixeira de Freitas, e-mail alexandrefreitas@ufpr.br titativo para o vírus da hepatite B com 227 cópias $/ \mathrm{mL}$, contagem de linfócitos T CD4 com 515 células/ $\mu$ e PCR quantitativo para o HIV com nível não detectável. Realizou imunossupressão com ciclosporina, micofenolato mofetil e prednisona. Para o manejo da hepatite B recebeu 10000 unidades de globulina hiperimune para o vírus da hepatite B (HBIG) no per-operatório, durante a fase anepática, 10000 unidades no pós-operatório, após a admissão na UTI e 10000 unidades por dia durante uma semana.

No pós-operatório apresentou nível não detectável de HBsAg e anti-HBs maior do que $1000 \mathrm{mUI} / \mathrm{mL}$. Como terapia antiretroviral recebeu tenofovir, amprenavir e ritonavir. Apresentou boa evolução e recebeu alta no $10^{\circ}$ dia de pós-operatório com plano de administração de HBIG conforme o protocolo do estudo multicêntrico para transplantes de órgãos sólidos em portadores de HIV coordenado pela Universidade da Califórnia em São Francisco ${ }^{4}$.

\section{DISCUSSÃO}

Nos últimos anos foram publicados alguns estudos demonstrando sobrevida semelhante após o transplante hepático em pacientes soropositivos e soronegativos para o HIV ${ }^{2,3}$. Na Espanha, a indicação de transplante hepático em portadores de HIV deve obedecer alguns critérios (Figura 1) ${ }^{1}$. No período pós-transplante existe a necessidade de continuidade da terapia antiretroviral. Deve-se escolher regime com baixa possibilidade de interação farmacológica com os imunossupressores e baixa toxicidade renal e hepática. 
Pacientes sem indicação de terapia antiretroviral altamente ativa - Contagem de CD4 > 350 células/ $\mu \mathrm{l}$

Pacientes com indicação de terapia antiretroviral altamente ativa

- Ausência de infecção oportunística característica da AIDS com exceção da tuberculose, candidíase esofágica e pneumonia por P. jiroveci

- Contagem de CD4 > 100 células/ $/ 1^{*}$

- Carga viral indetectável no plasma $(<50$ cópias $/ \mathrm{mL})$ no momento do transplante

- Realização de tratamento eficaz para o HIV no pós-operatório

* Nos pacientes que apresentaram tuberculose, candidíase esofágica e pneumonia por P. jiroveci a contagem de CD4 deve ser $>200$ células/ $\mu 1$

FIGURA 1 - Critérios para indicação de transplante hepático em pacientes soropositivos para o HIV

Para a realização de transplante hepático em portadores de hepatite B a carga viral pré-operatória deve ser menor do que 102 ou 103 cópias $/ \mathrm{mL}^{3}$. Isso é obtido com antivirais como a lamivudina, o adefovir, o tenofovir e o entecavir.
Nos pacientes que apresentam co-infecção com o HIV e com o vírus da hepatite $\mathrm{B}$ a terapia antiretroviral altamente específica, quando indicada, deve incluir a lamivudina ou outro antiviral com ação contra o vírus da hepatite B. Existe preocupação em relação ao desenvolvimento de resistência à lamivudina no período pré-transplante. Se possível, a indicação de transplante hepático deve ser precoce, antes do desenvolvimento de resistência. Nos casos de ocorrência de resistência o tratamento com adefovir, tenofovir ou entecavir é eficiente e seguro antes e depois do transplante ${ }^{2,3}$.

\section{CONCLUSÃO}

O transplante de fígado está indicado em casos selecionados de pacientes soropositivos para o HIV que apresentam doença hepática avançada.

Freitas ACT, Sobottka W, Parolin MB, Matias JEF, Coelho JCU. Liver transplantation in an HIV positive patient. ABCD Arq Bras Cir Dig 2009;22(3):175-6

ABSTRACT - Background - With the advent of highly active antiretroviral therapy and improved ability to prevent HIV-related complications, transplantation of HIV-infected patients has been done in selected cases. Case report - To report a case of an HIV infected patient submitted to liver transplantation due to liver cirrhosis and hepatocellular carcinoma secondary to hepatitis B infection. He was on antiretroviral and hepatitis B therapy and never presented opportunistic infections. Conclusion - Liver transplantation can be indicated in special cases of HIV positive patients with advanced hepatic disease.

HEADINGS - Liver transplantation. Liver cirrhosis. HIV.

\section{REFERÊNCIAS}

1. Miró JM, Torre-Cisnero J, Moreno A, Tuset M, Quereda C, Laguno M, Vidal E, Rivero A, Gonzalez J, Lumbreras C, Iribarren JA, Fortún J, Rimola A, Rafecas A, Barril G, Crespo M, Colom J, Vilardell J, Salvador JA, Polo R, Garrido G, Chamorro L, Miranda B. GESIDA/GESITRA-SEIMC, PNS and ONT consensus document on solid organ transplant (SOT) in HIV-infected patients in Spain (March, 2005). Enferm Infecc Microbiol Clin. 2005 Jun-Jul;23(6):353-62.

2. Neff GW, Bonham A, Tzakis AG, Ragni M, Jayaweera D, Schiff ER, Shakil O, Fung JJ. Orthotopic liver transplantation in patients with human immunodeficiency virus and end-stage liver disease. Liver Transpl. 2003 Mar;9(3):239-47.
3. Terrault NA, Carter JT, Carlson L, Roland ME, Stock PG. Outcome of patients with hepatitis B virus and human immunodeficiency virus infections referred for liver transplantation. Liver Transpl. 2006 May;12(5):801-7.

4. Transplant study for people with HIV [homepage internet]. São Francisco: University of California; [atualizada em 2007 aug; acesso em 2007 sep 20]. Solid organ transplantation in HIV: multi-site study; [aproximadamente 83 telas]. Disponível em: http://www.hivtransplant.com/files/U01_Protocol_6.0.pdf

Fonte de financiamento: não há Conflito de interesse: não há Recebido para publicação: 07/01/2009 Aceito para publicação: 20/02/2009 